\title{
Coerência corporativa e diversificação via fusões e aquisições: um exame para empresas líderes da indústria manufatureira norte-americana nos anos 90
}

Mariana Iootty DeCE/UFRRJ e IE/UFRJ

Francisco Ebeling IE/UFRJ

\author{
Palauras-chave \\ fusões e aquisições, \\ diversificação, coerência \\ corporativa.
}

Classificação JEL L10, L20, L60.

Key words

mergers and acquisitions,

diversification, corporate coherence.

JEL Classification L10, L20, L60.

\section{Resumo}

Este trabalho investiga a coerência no processo de diversificação corporativa via fusões e aquisições (F\&A), e analisa as razões pelas quais a firma tende, na maioria das vezes, a incorporar ao seu portfolio atividades relacionadas às já existentes. Com base na concepção "penrosiana" da firma, o trabalho argumenta que por intermédio das operações de F\&A, a firma, embora tenha a opção de realizar um caminho conglomerado de diversificação, e em alguns casos isto ocorra, tende a imprimir uma diversificação não aleatória (coerente) em resposta a condicionantes internos definidos pela natureza específica de suas características produtivas e tec- nológicas. O trabalho fornece suporte empírico para os argumentos apresentados através de um estudo cross-section baseado numa amostra de 106 empresas de origem norte-americana, líderes da indústria manufatureira, e as operações de F\&A por elas desenvolvidas nos EUA no período 1990-1999.

\section{Abstract}

This paper sheds light on the coherent nature of the diversification process of firms through mergers and acquisitions, and analyses the reasons why firms tend to include related activities in their production portfolios. Based on Penrose's ideas, it argues that even through M\& A transactions, firms tend to determine a coherent (non-random) path of growth due to the internal conditionings defined by their productive and technological characteristics. The paper gives empirical support for these arguments through a cross section analysis, based on a sample of 106 big corporations from the manufacturing industry in the USA and their M\&A transactions carried out in the period 1990-1999. 


\section{Introdução}

A existência de grandes corporações diversificadas é um traço marcante da economia moderna. Análises históricas indicam a relevância de corporações diversificadas nos EUA, no Reino Unido e na Alemanha, ao menos para os anos 60 e 70 (Chandler, 1990). Mais recentemente, como ressalta Montgomery (1994), mesmo depois da tendência de recentralização corporativa observada nos EUA, nos anos 80, as firmas norte-americanas permanecem com elevado grau de diversificação: em 1992, o número médio de linhas de atividades operadas pelas 500 maiores empresas de capital aberto nos EUA era de 10,9.

$\mathrm{Na}$ análise sobre este tema, um aspecto relevante a ser examinado consiste na tendência das firmas de privilegiarem a diversificação não aleatória (coerente) de suas atividades, ao adicionarem ao seu portfolio atividades que sejam relacionadas às já existentes. Assim sendo, parece ser intrigante examinar, dos pontos de vista teórico e empírico, por que, por exemplo, empresas atuantes no setor petrolífero tendem, na maioria das vezes, a diversificar para áreas relacionadas, como atividades petroquímicas, e não para áreas não relacionadas, como de informática.

Para então analisar a coerência no processo de diversificação, o presente tra- balho focaliza as operações de fusão e aquisição (F\&A) como instrumentos de expansão corporativa, e procura responder por que a firma tende a manter coerência no seu processo de diversificação, até quando esse se dá por intermédio de F\&A. Com esse objetivo, o artigo parte da visão penrosiana da firma para encontrar nos condicionantes internos a essa, mais especificamente nas suas características tecnológicas e produtivas, uma possível explicação para esse fato.

O artigo está dividido em cinco grandes seções, além desta introdução. Na primeira delas são apresentados alguns argumentos teóricos que embasam a formulação de uma hipótese a ser testada empiricamente. Na seção seguinte é apresentada a metodologia de análise a ser aplicada. $\mathrm{Na}$ terceira e quarta seções são apresentados os resultados alcançados. A quinta e última seção resume as principais conclusões obtidas.

\section{1_Processo de diversificação: possíveis direções, seus limites e a coerência corporativa}

Segundo Penrose (1959), o processo de diversificação das atividades produtivas da firma haveria de se dar em torno das suas áreas de especialização, definidas pela base técnica/tecnológica utilizada e 
pelos mercados para os quais a produção é direcionada. ${ }^{1}$ Seguindo então essa interpretação, haveria duas possíveis direções para a diversificação corporativa.

$\mathrm{Na}$ primeira delas, a diversificação aprofundaria a área de especialização já existente, caracterizando um movimento da firma em direção a indústrias no interior das suas bases tecnológicas e/ou de mercado e na direção de indústrias vizinhas do ponto de vista dessas bases de mercado e técnica (Guimarães, 1982, p. 64). Em ambos os casos, segundo Penrose (1959), a diversificação estaria relacionada à natureza dos recursos existentes e aos tipos do serviço produtivo que eles podem gerar. Tal direção assumida pela firma diversificante seria então relacionada ou concêntrica, como denominou Wood (1971). ${ }^{2}$ Esse caminho concêntrico de diversificação, quando concretizado por meios externos de expansão, ${ }^{3}$ corresponde- ria, em termos práticos, à realização de F\&A relacionadas, por meio das quais a firma adquirente estaria adicionando atividades que possuem características comuns em termos de produto e tecnologia.

A segunda das direções possíveis para a diversificação corporativa corresponderia à entrada em novas áreas de especialização, o que representaria o ingresso da firma em novas atividades que não se relacionam com as suas antigas bases tecnológicas e de mercado. Nesse caso, a diversificação seria não relacionada ou conglomerada. Quando a firma utilizasse meios externos para diversificar suas atividades, essa direção não relacionada traduzir-se-ia, em termos práticos, pelas operações de F\&A conglomeradas, que envolvem firmas essencialmente divergentes, seja em termos de especialização produtiva, seja em termos de especialização tecnológica.
1 A base técnica, de acordo com Penrose, pode ser entendida como cada tipo de atividade produtiva da firma que utiliza máquinas, insumos, processos, capacitações e conhecimentos complementares no processo de produção. Nesse sentido, "tanto induistrias diferentes podem possuir a mesma base técnica, quanto a mesma indústria pode possuir diferentes bases tecnológicas"
(Penrose, 1959, p. 109). A base de mercado, por sua vez, consiste em "cada grupo

de consumidores que a empresa pretende influenciar com um mesmo programa de vendas" (Penrose, 1959, p. 109). Seguindo essa definição, os mercados seriam conceituados de acordo com o tipo de consumidor que a empresa atende. Desta forma, um mesmo mercado pode incluir várias bases de mercado.
2 A diversificação concêntrica, segundo Wood (1971), representaria a diversificação em direção ou ao mercado existente da firma (mercado-concêntrica) ou ao uso de uma tecnologia similar a atualmente utilizada (tecnológica-concêntrica) (Wood, 1971, p. 428 e 429).

3 Vale ressaltar aqui que o artigo assume a idéia de que as operações de F\&A representam uma maneira de expansão alternativa à forma endógena de crescimento.

Por intermédio de transações desse tipo, a firma poderia aplicar suas competências para manusear seus recursos ociosos e para acessar recursos e competências detidos por outras empresas, o que, em termos práticos, se traduziria pelo acesso a novas plantas produtivas e pela entrada em novos mercados. 


\section{1_Coerência na diversificação: a escolha da direção relacionada}

Embora seja possível vislumbrar as duas possíveis direções da diversificação (relacionada ou conglomerada), alguns estudos, como o realizado pela própria Penrose, e outros que caracterizam a firma pelos seus limites e ativos específicos (Winter, 1987), ou pelo seu escopo multiproduto (Teese, 1982), apontam que as empresas, na maioria das vezes, diversificam suas atividades de forma não aleatória, no sentido de privilegiar o caminho relacionado em detrimento do conglomerado. Em termos empíricos, essa não-aleatoriedade foi bem documentada. Lemelin (1982), Scott (1983) e MacDonald (1985) apresentam evidências de que firmas tendem a diversificar de forma coerente ao aproveitarem as similaridades em termos de marketing, distribuição e $P \& D$, existentes entre as atividades de origem e destino. Chandler (1990), por sua vez, documentou casos de empresas que, ao longo do século XX, cresceram justamente em função da adoção de uma direção relacionada de diversificação, por intermédio da qual foi possível crescer com a obtenção concomitante de economias de escala e escopo. Na mesma direção, outros autores apresentaram evidências que sugerem a superioridade da diversificação relacionada sobre a não relacionada. Rumelt (1974), por exemplo, constata que as firmas multiprodutoras que perseguem uma estratégia relacionada de diversificação possuem performance superior `aquelas que escolhem um caminho conglomerado. Estudos mais recentes encontram resultados similares: Wernerfelt e Montgomery (1988) demonstraram que firmas cujo portfolio produtivo é mais estreito (relacionado) alcançam um valor maior (medido em termos da taxa $q$ de To$\left.\mathrm{bin}^{4}\right)$ do que firmas conglomeradas.

Assim como no processo de crescimento orgânico, na maior parte das vezes, parece também haver certa lógica na maneira como as firmas direcionam sua diversificação por intermédio da forma externa de expansão, i. e., por intermédio das operações de F\&A. São assim freqüentes os exemplos de aquisições de empresas do setor petroquímico por parte de empresas que operam no setor de petróleo, mas são poucos os casos em que as empresas do setor de alimentos adquirem empresas do setor petroquímico.

Embora a constatação desse fato possa encontrar respaldo empírico, não há ainda, do ponto de vista teórico, uma interpretação concisa sobre tendência não aleatória do processo de diversificação. A vertente neoclássica da Economia Industrial [ver, por exemplo, Tirole (1998)] assume postura praticamente silenciosa a esse respeito. Como bem ressaltado em Montgomery (1994), os 4 Em termos simples, a taxa $q$ de Tobin pode ser entendida como a razão entre o valor de mercado da firma e o custo de reposição dos seus ativos. 
modelos de Economia Industrial convencionais parecem se "sentir mais à vontade" com a idéia de firmas de produtos homogêneos, não considerando, portanto, a existência de firmas com múltiplos portfolios produtivos, e muito menos a observação de uma ordem lógica na formação destes últimos. No que se poderia identificar como uma tentativa isolada dessa vertente ortodoxa para compreender a natureza não aleatória na definição do perfil multiprodutor da firma, Panzar e Willig (1982) apresentam o conceito de economias de escopo referente à função de custo da firma. Entretanto, por se basear em um conceito estático, tal iniciativa se demonstra insuficiente para compreender a lógica da definição do portfolio produtivo da firma conquanto um processo. ${ }^{5}$ Nesse sentido, o quase total afastamento da vertente ortodoxa da Economia Industrial em relação à discussão da coerência corporativa talvez se explique pelo fato de ela focalizar como objeto de análise o agregado do mercado, normalmente interpretado como a média da população das firmas, e não a firma individual em si e sua dinâmica multiprodutora.

$\mathrm{Na}$ tentativa de preencher essa lacuna, Teece et al. (1994) introduzem o conceito de coerência, formalizando-o como uma contrapartida dinâmica à noção ortodoxa de economias de escopo. Partindo da visão da firma baseada em competências, esses autores argumentam que o crescimento da firma é geralmente balanceado no sentido de permitir coerência entre as atividades existentes e aquelas a ser adicionadas ao portfolio produtivo. A coerência observada na estratégia de diversificação da firma refletir-se-ia na presença de características tecnológicas e de mercado comuns entre as linhas atualmente operadas e perseguidas pela firma (Teece, et al., 1994, p. 4). Desta forma, a presença de coerência evidenciaria a obediência ao caminho relacionado de diversificação. ${ }^{6}$
5 Panzar e Willig (1982)

examinam a função de custos da firma para declarar que a existência de economias de escopo dá origem a firmas multiprodutoras, uma vez que a produção conjunta de dois bens pela mesma empresa é menor do que os custos combinados de duas firmas especializadas. De acordo com Teece (1980), tal análise se

\section{demonstra insuficiente}

para compreender a dinâmica da definição dos limites de uma firma multiprodutora, uma vez que a função de custos, embora seja capaz de resumir toda a informação relevante sobre a tecnologia de produção da firma, não é suficiente para sintetizar a tecnologia organizacional da empresa.
6 A respeito da noção de coerência corporativa introduzida por esses autores, vale destacar dois pontos importantes. Primeiramente, ela é definida a partir da existência de múltiplos produtos, e nesse sentido a coerência cresce quando o número de características tecnológicas e de mercado encontradas entre diferentes linhas de atividades $\ldots \ldots \ldots \ldots$ aumenta. O segundo ponto diz respeito à diferença entre coerência e especialização produtivas: de acordo com os autores, como a noção de coerência reflete a dimensão de vários produtos, a especialização produtiva consiste num caso especial da coerência quando esta se restringe a uma única linha de produtos (Teece et al., 1994, p. 4). 
Com base nessa percepção de coerência, a próxima seção pretende explicar por que a firma em seu processo de expansão e diversificação, de modo geral, e, mais especificamente, quando a expansão se dá mediante o uso de operações de F\&A, tende a seguir uma direção relacionada. Serão apresentados e concatenados alguns argumentos que focalizam a ótica interna da firma e que podem ser úteis para a compreensão deste ponto.

\section{2_ Condicionantes internos à firma: a relevância das características tecnológicas e produtivas da firma e a coerência no processo de diversificação via F\&A}

Como disposto em Penrose (1959), Guimarães (1982) e Teece (1982), as firmas diversificam porque essa é a melhor alternativa para aproveitar os seus recursos excedentes na procura pela realização do seu potencial de crescimento. A presente seção pretende demonstrar que, muito embora a firma tenha a possibilidade de adotar um caminho conglomerado de diversificação produtiva - por intermédio do qual seriam alcançados, por exemplo, ganhos de sinergia financeira e diversificação dos riscos operacionais -, na maior parte das vezes ela acaba adotando um caminho relacionado (até quando a diversificação se dá via $F \& A$ ), em função das restrições impostas pela natureza específica de seus recursos internos.

Vale aqui ressaltar que a apresentação dos argumentos que se seguem não pressupõe a inexistência de casos de firmas conglomeradas bem-sucedidas, construídas até mesmo por intermédio de F\&A. Se uma empresa em particular consegue tirar vantagem dos benefícios da diversificação não relacionada, seja por via orgânica, seja por meio externo, isso depende certamente do talento individual dos gerentes e da história e cultura da instituição. Contudo, o que se vai alegar em seguida é que o caso geral parece favorecer a tendência de obediência aos limites internos da firma, no sentido de que a diversificação corporativa privilegie a adoção de um caminho relacionado ao portfolio já desenvolvido pela empresa em questão.

De acordo com a interpretação penrosiana, os recursos ociosos, com os quais a firma procura expandir suas atividades, são específicos. A natureza particular desses recursos excedentes e de suas competências derivadas dificultaria a escolha de uma direção indiscriminada de diversificação, condicionando assim a firma a assumir, na maioria das vezes, a direção relacionada de diversificação, definida no interior da sua área de especialização corrente.

Duas considerações relevantes devem ser destacadas para explicar mais pre- 
7 Aqui, mais uma vez, ficam evidentes as dificuldades que a teoria neoclássica enfrenta para explicar os processos decisórios de uma empresa. A crítica de Sraffa (1926) desmantela o esquema neoclássico que pressupõe retornos marginais

decrescentes ao capital, admitindo a existência de economias de escala internas à firma. Ao fazê-lo, mais além, reconhece o caráter finito de possíveis técnicas de produção se considerado um conjunto de firmas, cada uma atuante numa determinada escala de produção, e, portanto, capazes de auferir um nível distinto de ganhos dessas economias de escala. Os processos de F\&A são também motivados pelo desejo da firma de aumentar sua escala empresarial, em outras palavras, de diferenciar e tornar sua técnica de produção pouco imitável e acessível às concorrentes, evidenciando também que amplas e ilimitadas alternativas produtivas/tecnológicas se escasseiam, à medida que as empresas se concentram nesse processo. cisamente por que a natureza específica dos recursos da firma acabaria condicionando-a a configurar suas atividades de forma não aleatória.

A primeira delas se refere aos limites da firma e a essência path dependent do seu processo de aprendizado. De acordo com Teece et al. (1994), os investimentos prévios e o repertório de rotinas empregadas pela firma em seu processo de aprendizado acabaria restringindo o comportamento futuro da empresa. Assim sendo, como a firma constrói com base naquilo que ela já sabe, a sua história seria importante fator limitativo de escolhas. Isto é, a firma definitivamente não possui um menu neoclássico de amplas e ilimitadas alternativas produtivas/tecnológicas, mas sim um leque de alternativas restritas pelas suas opções passadas (Langlois, 1995, p. 91). ${ }^{7}$ Em outras palavras, aquilo que ela escolheria fazer no futuro dependeria do que ela escolheu fazer no passado (Kay, 1997, p. 63). Nesse sentido, as mesmas características que possibilitam a firma extrair diferenciais de renda com base em seus recursos também tornariam difícil para a mesma transferir esses recursos para linhas de atividade não relacionadas (Mowery et al., 1998). Como conseqüência, as possibilidades de investimento em novas atividades estariam próximas aos recursos e às atividades prévias
(Teece et al., 1994, p. 21). Seguindo então essa lógica, a essência de path dependent também se faria notar na direção da expansão corporativa, e, assim sendo, a trajetória de expansão da firma tenderia a seguir, de alguma forma, o portfolio de atividades já operadas.

A segunda consideração diz respeito ao fato de que iniciativas de diversificação não relacionada baseada no uso dos recursos específicos da firma tenderiam a gerar benefícios marginais decrescentes, tornando, portanto, a opção de diversificação relacionada mais vantajosa.

Como discutido em Penrose (1959) e Teece (1980 e 1982), a diversificação, assim como o crescimento num sentido mais geral, seria direcionada pelo aproveitamento de recursos ociosos que decorrem da característica indivisível desses. Argumenta-se, assim, que o aproveitamento das economias de escopo associadas à exploração desses recursos tenderia a um limite no caso de eles serem utilizados em atividades diferentes e "distantes" daquela originalmente desenvolvida pela firma (Wernerfelt e Montgomery, 1988). Mais precisamente, Wernerfelt e Montgomery (1997) postulam que, durante o processo de diversificação produtiva, quanto mais a firma se distancia de seu escopo original, ceteris paribus, maiores serão as perdas de eficiência e menores serão as vantagens competitivas conferidas 
pelos fatores produtivos detidos. Isto é, se a firma diversifica, ela transfere recursos em excesso para a área de atividade mais próxima que ela pode explorar. Se o excesso de recursos persiste, ela direcionará sua expansão para linhas de atividades mais distantes, até o ponto em que as rendas operacionais obtidas tornam-se subnormais. Assim sendo, a firma que transfere seu excesso de capacidade para mercados distantes tende a obter, no limite, reduzidos ganhos marginais (Wernerfelt e Montgomery, 1997, p. 175-176). Em outras palavras, como disposto em Gary (1988, p. 4), os potenciais benefícios da diversificação, que se relacionam às economias de escala e escopo decorrentes do excesso de recursos da firma, tenderiam a diminuir em resposta a uma diversificação direcionada para áreas distantes das atividades centrais.

Isso ocorreria por duas razões apresentadas em Teece (1980). Primeiramente, no caso em que as economias de escopo obtidas via diversificação são baseadas no uso do recurso capital humano (ou no conhecimento, de modo geral), haveria um limite decorrente do congestionamento no acesso ao referido recurso produtivo. Embora o uso do capital humano para o desenvolvimento de atividades diferentes não esteja associado a uma redução no seu valor, por outro lado, ele se relaciona a uma ele- vação dos custos em função do congestionamento na comunicação. Nesse sentido, à medida que o conhecimento de uma firma é cada vez mais demandado por diferentes atividades, surgiriam gargalos sob a forma de cientistas, engenheiros e gerentes com qualificações extremamente generalizadas, o que limitaria, em alguma ocasião, a lucratividade da diversificação das atividades (Teese, 1980, p. 60). Em segundo lugar, economias de escopo baseadas no compartilhamento de ativos físicos indivisíveis chegariam a um limite porque tais tenderiam a alcançar mais rapidamente, em algum momento, a plena utilização, impossibilitando, portanto, o alcance posterior de qualquer ganho adicional no processo de diversificação para atividades diferentes daquela inicial (Teese, 1980). ${ }^{8}$ Como conseqüência, quanto mais conglomerada a diversificação produtiva da firma, menores seriam os retornos marginais decorrentes.

$\mathrm{Na}$ mesma direção dessa interpretação, Penrose (1959), ao discutir a existência de benefícios marginais decrescentes da diversificação não relacionada, argumenta ainda que:

...a firm may go into many fields, but to maintain itself against competitive pressures it must be prepared to continue putting new funds into each field. This need for continuous

\footnotetext{
Vale lembrar que as.....

8 Vale lembrar que as

economias de escopo

obtidas mediante o compartilhamento de ativos físicos indivisíveis entre diferentes atividades também estariam limitadas no caso do tamanho do mercado crescer acima da capacidade de produção dos referidos ativos.
} 
new investment will restrict the number of fields a firm can support any given time. The further from its existing areas of specialization it goes, the greater the effort required of the firm to attain the necessary competence... (Penrose, 1959, p. 134).

Assim sendo, a lucratividade e até mesmo a sobrevivência de uma firma que escolha produzir um número de produtos não relacionados do ponto de vista produtivo e tecnológico dependeria em demasia da habilidade dos gerentes de manter recursos suficientes para a manutenção da competitividade nos múltiplos mercados que opera. ${ }^{9}$ A firma conglomerada teria então de realizar naturalmente revisões acerca das linhas de produtos que opera, e cortes teriam de ser efetivados de modo a conservar a lucratividade das atividades que ela deseja continuar a operar (Penrose, 1959, p. 137). ${ }^{10}$ Haveria, desse modo, limites para a amplitude da diversificação produtiva. A tendência seria, portanto, a manutenção da coerência corporativa.

O fato de a natureza específica dos recursos da firma condicionar a direção da diversificação adotada por ela também se faria valer no caso do crescimento por vias externas, i. e., por intermédio de F\&A. Isso porque, como ressaltado em Wood (1971, p. 435), é bastante razoável supor que a direção e a extensão da diversificação realizada por meios de operações de F\&A sejam reflexos diretos da expansão interna da firma. ${ }^{11}$ Embora a firma que escolha crescer

\footnotetext{
9 Esse elevado grau de

habilidade de um empresário, num esquema Schumpeteriano de concorrência e ciclos, resultaria numa

"ultrapassagem" daquela empresa por outras cujos empresários lograssem facilitar mais os processos empresariais de suas respectivas empresas sem diversificações desnecessariamente distantes de seus core businesses empresariais, se considerarmos a habilidade do empresário ou empreendedor como
}
competência essencial para o sucesso de uma firma. Em outras palavras, a excessiva diversificação tenderia ao fracasso da empresa porque empresários de outras conseguiriam realizar tarefas de administração com menor dificuldade.
10 Nesse sentido, vale destacar aqui que Penrose (1959) assume a existência de um limite para a diversificação da firma, e não a existência de um limite para o tamanho da firma. A respeito dessa possibilidade de um

$\begin{array}{ll}\text { tamanho ótimo produtivo, a } & \text { possivelmente já possuem uma } \\ \text { autora discorda plenamente, ao } & \text { robustez maior. Admite-se que } \\ \text { afirmar que não existe nada } & \text { o tamanho de uma empresa se } \\ \text { inerente à natureza da firma e } & \text { relaciona ao capital próprio que } \\ \text { da sua função econômica que a } & \text { ela possui. Quanto maior essa } \\ \text { previna de expandir } & \text { magnitude, maior a capacidade } \\ \text { indefinidamente seu tamanho. } & \text { de essa empresa captar crédito } \\ 11 \text { A etapa em que uma firma } & \text { junto a emprestadores. } \\ \text { opta pela diversificação por } & \text { Como as F\&A muitas vezes } \\ \text { meio de fusões e aquisições } & \text { dependem desse tipo } \\ \text { pode ser entendida como uma } & \text { de recurso financeiro, } \\ \text { etapa posterior àquela em que } & \text { supõe-se que, para incorrer } \\ \text { opta pela diversificação por } & \text { nessa decisão de adquirir ou } \\ \text { intermédio do simples } & \text { fundir-se com outra, } \\ \text { crescimento orgânico, uma } & \text { uma empresa deve possuir } \\ \text { etapa em que as empresas } & \text { certo tamanho. }\end{array}$


via $\mathrm{F} \& \mathrm{~A}$ esteja à procura de recursos que ela não dispõe, como, por exemplo, o conhecimento em uma determinada atividade produtiva, ela o faz com base nos recursos específicos que possui, o que certamente tende a condicionar a direção do crescimento. Sendo assim, Penrose (1959) argumenta que, apesar de as operações de F\&A representarem excelente instrumento para a diversificação produtiva, elas não permitem a adoção de uma direção indiscriminada. Em termos práticos, tais limites implicariam que:

...no firm can acquire every likely firm in sight in any given period of time; it must choose, and since mistakes may be costly and not always reparable, it will choose those enterprises which seem most likely to complement or supplement its existing activities... (Penrose, 1959, p. 129)

Seguindo essa mesma linha de interpretação, Wernerfelt (1997), mais recentemente, argumenta que, numa operação de F\&A, a firma adquirente possui dificuldade para investigar os recursos detidos pela firma-alvo; identificar quais deles seriam vantajosos para exploração, e, mensurar, ainda que de forma bastante vaga, os custos envolvidos nesse possível processo de aproveitamento. Assim sendo, a firma compradora freqüentemente limitaria sua busca em direção a alvos capazes de assumir relações de suplemento, para ampliar o acesso a recursos já possuídos, ou para acessar recursos combináveis com os já detidos. Nesse sentido, as firmas tenderiam então a exibir coerência corporativa ao adicionar, mediante as operações de F\&A, atividades relacionadas em termos tecnológicos e produtivos às suas linhas de negócios já operadas.

Em função dos argumentos anteriormente apresentados, é possível alegar, de modo geral, que firmas tendem a desenvolver F\&A relacionadas no sentido de respeitar suas características internas. Assim sendo, ao realizarem $\mathrm{F} \& \mathrm{~A}$, as firmas teriam suas escolhas (referentes às empresas "alvos" ou "parceiras") restritas pelas suas características internas, o que lhes determinaria selecionar outras empresas que possuíssem características semelhantes ou complementares às suas.

Nesse sentido, com base na concepção teórica de coerência corporativa discutida em Teece et al. (1994), entende-se que a coerência de um caminho de diversificação via operações de F\&A deve ser retratada a partir das semelhanças produtivas e tecnológicas entre as firmas envolvidas na referida operação. Assim, supõe-se que: 
$\because \ldots \ldots \ldots \ldots$

12 A lista das 106 empresas

analisadas encontra-se em anexo.

13 Para cada transação registrada, tal base fornece: ano de transação, nome das empresas adquiridas e compradoras, percentual de ações transacionadas e valor da transação. As 106 firmas norte-americanas da amostra foram responsáveis por 2.488 operações realizadas nos EUA, nos anos 90, respondendo por $11,6 \%$ de todas as transações realizadas na indústria manufatureira norteamericana no mesmo período.
(H1) semelhanças tecnológicas e produtivas entre firmas ajudam a explicar a realização de F\&A entre elas.

\section{2_ Metodologia}

\subsection{Objeto de análise e bases de dados}

De forma a delimitar ao máximo o objeto específico a ser examinado, focalizaramse inicialmente os EUA e a década de 90 como país-alvo e período-alvo. Como o objetivo do estudo é avaliar empiricamente o processo de crescimento ao nível da firma, optou-se por delimitar o objeto de análise em uma amostra de firmas de origem norte-americana que tivessem participado intensivamente do processo de F\&A nos EUA, na década de 90.

A escolha das firmas da amostra foi realizada com base em três critérios. Primeiramente, as empresas deveriam apresentar relevância econômica em termos de tamanho durante os anos 90. Em segundo lugar, de forma a definir uma amostra com corporações dinâmicas, essas empresas deveriam ter apresentado significativo desempenho tecnológico. Finalmente, tais empresas deveriam estar distribuídas entre os principais setores da indústria manufatureira norte-americana.
O objeto de análise foi assim estabelecido como uma amostra de 106 grandes firmas norte-americanas que operam na induistria manufatureira e que realizaram transações de F\&A nos EUA, na década de $90 .{ }^{12}$ Valendo-se dessa definição, foi então construída uma base de dados tendo em vista cinco diferentes fontes de informação, que são descritas a seguir.

Em primeiro lugar, foram utilizadas as listagens da Fortune 500 dos anos 90, para recolher informações sobre receita de vendas e ativos das empresas. Em segundo lugar, foi utilizada a base de dados fornecida pela Thomsom Financial Securities Data (TFSD), que disponibiliza informações sobre operações de F\&A realizadas nos EUA para o período 1990-1999. ${ }^{13}$ A terceira das fontes de informações utilizada corresponde a base de dados Who Owns Whom (WOW) da Dun \& Bradstreet, que compreende, para o ano de 1999, registros referentes às maiores corporações dos EUA, incluindo, para cada corporação, informações sobre a "árvore" da firma (matriz e subsidiárias), e o número de empregados alocados para cada categoria SIC de atividade. A quarta base de dados é o Volume II da US Corporate R\&D Report da National Scientific Foundation (NSF), que fornece, para cada uma das 500 maiores empresas dos EUA em termos de atividades de P\&D, as 
receitas de vendas e os gastos em P\&D para os anos de 1996 e 1997. Finalmente, a quinta fonte de informação é a base de dados de patentes da Universidade de Reading (Inglaterra), que registra, para o intervalo 1969-1995, as patentes depositadas nos EUA - ou mais precisamente no US Patent and Trademark Office, (USPTO). ${ }^{14}$

A escolha de uma amostra de firmas norte-americanas é particularmente conveniente em função de alguns argumentos. Primeiramente, pela representatividade da economia norte-americana na economia mundial, em que é evidente a importância das F\&A como mecanismo de consolidação e expansão das atividades empresariais, mais do que em outros países. Assim, as F\&A, conquanto mecanismo de diversificação empresarial, ocorrem numa quantidade sobreproporcional, o que oferece vantagens analíticas e estatísticas importantes. Em segundo lugar, tal país, pela sua cultura empresarial avançada, cultua também o hábito de reunir e divulgar ampla quantidade de informações. Desse modo, não é imposta uma barreira informacional à execução deste artigo. Por fim, a escolha de uma amostra de firmas norte-americanas foi decisivamente interessante porque as fusões e as aquisições praticadas naquele país inter- relacionam empresa comprada e empresa compradora das formas mais diferentes possíveis. Em outras palavras, com a grande diversidade e heterogeneidade de empresas atuantes naquele país, é muito grande a gama de possíveis arranjos praticados por empresas adquiridas e adquirentes. Assim, assiste-se aos mais diferentes tipos de F\&A, o que permite extrair uma amostra com bastante diversidade.

\section{2_ Unidade e variáveis de análise}

Como visto anteriormente, a hipótese formulada no trabalho trata da coerência no processo de diversificação via F\&A e prevê, em termos específicos, que a firma tende a respeitar suas características internas ao desenvolver transações de F\&A com outras empresas com as quais possua similaridades produtivas e tecnológicas. Isso refletiria, então, a influência dos condicionantes internos à firma sobre a definição de uma direção coerente (relacionada, concêntrica) para a diversificação via $F \& A$.

Nesse sentido, como a hipótese $H 1$ pretende associar diversificação via $\mathrm{F} \& A$ às semelhanças produtivas e tecnológicas entre duas firmas engajadas na referida operação, a unidade de análise deve compreender transações de F\&A entre dadas
14 Seguindo essa fonte de informação, as 106 empresas $\mathrm{da}$ amostra respondem por 9,2\% do total das patentes depositadas na USPTO para o mesmo intervalo de tempo. 
15 Para efeito de formalização, as unidades de análise são geradas a partir das $\left(\begin{array}{c}106 \\ 2\end{array}\right)$ combinações.

16 Como visto no início da seção metodológica, para cada uma das 106 firmas da amostra, são consideradas não somente a matriz, mas também as suas subsidiárias. Nesse sentido, para se registrar a realização de uma transação de F\&A em cada par, entre os 5.565 possíveis, são avaliadas as possibilidades de todas as transações entre as subsidiárias e as matrizes das duas firmas envolvidas no referido par. duas firmas, e não o nível das firmas individualmente.

Como forma de viabilizar a criação de um grupo de controle, utiliza-se o recurso de geração de combinação binária de firmas a partir das empresas analisadas. Assim sendo, com base nas 106 firmas da amostra, existem 5.565 possíveis combinações (duas a duas) entre elas. ${ }^{15}$ Desta forma, a unidade de análise não compreende o nível das 106 firmas, mas sim os 5.565 possíveis pares construídos entre elas. A partir disso, serão então construídas cinco variáveis ao longo dessas combinações binárias de firma.

A primeira delas corresponde a variável $(F \& A)$ que indica, para cada um dos 5.565 pares de firmas, se as duas empresas consideradas desenvolveram, ou não, entre elas ao menos uma transação de F\&A no período 1990-1999. ${ }^{16}$ Assim sendo, os 5.565 possíveis pares de firmas correspondem a possíveis transações de F\&A entre as firmas da amostra, e, com base na variável dicotômica (F\&A), é possível identificar os pares que efetivamente realizaram, entre si, ao menos uma operação de F\&A no período considerado. Foram assim identificados 132 pares de firmas que desenvolveram pelo menos uma transação de $\mathrm{F} \& \mathrm{~A}$, entre as 5.565 combinações possíveis.
A segunda das variáveis retrata a relação entre os perfis produtivos de um par de empresas (em uma possível transação de F\&A). De modo preliminar, são identificadas para cada uma das 106 empresas consideradas as suas três principais atividades SIC dois dígitos operadas, para as quais são alocadas o maior número de trabalhadores entre os trabalhadores totais da empresa. Após isso, finalmente ao nível das 5.565 combinações binárias de firmas, é então definida uma variável multicategórica $R P$ (para refletir a relação produtiva) que distingue entre:

i. pares de firmas que apresentam uma relação produtiva "próxima", possuindo em comum a principal linha de atividade SIC dois dígitos, entre as três reportadas;

ii. pares de firmas cuja co-especialização produtiva não é tão "próxima", possuindo em comum outro, mas não o principal, setor SIC;

iii. pares de firmas que não apresentam em comum nenhuma atividade SIC 2, entre as três reportadas.

A terceira variável diz respeito à relação tecnológica entre os pares de firmas. De forma preliminar, para examinar 
o perfil de competências tecnológicas de cada uma das 106 empresas da amostra, é utilizado, a exemplo do procedimento empregado em Jaffe (1986), Patel e Pavitt (1991; 1997; 1999) e Cantwell (1989; 1991), $\mathrm{o}$ indicador de vantagem tecnológica revelada (VTR). Por intermédio do uso de informações de patentes, tendo em vista a base de dados da Universidade de Reading, tal indicador reflete, para o período 1969-1995, a especialização tecnológica de cada firma em relação a 56 campos técnicos. Em termos mais precisos, para cada um dos campos técnicos onde a firma opera, o índice VTR é definido como a participação da empresa no total das patentes depositadas por todas as firmas analisadas naquela atividade, dividido pela participação da firma no total das patentes depositadas por todas as empresas em todos os campos técnicos da base de dados. Em outras palavras, esse índice capta a importância relativa de cada campo de competência tecnológica para a firma, após se levar em conta o volume total das competências da firma. Denotando Pij como o número de patentes depositadas no campo técnico $i$ pela firma $j$, então o índice VTR pode ser definido como:

$V \mathrm{TR}_{i j}=P_{i j} / \sum_{j} P i j / \sum_{i} P i j / \sum_{i j} P i j$
Partindo então do princípio de que o índice VTR permite calcular o perfil de competências tecnológicas de uma dada empresa, a mensuração da relação tecnológica entre as firmas dos 5.565 pares será feita por meio de um grau de correlação entre os seus respectivos perfis de competências tecnológicas. Tal relação pode ser calculada com base no coeficiente de correlação de Pearson entre as distribuições da variável $V T R$ para duas firmas de um par. ${ }^{17}$

Essa medida de correlação é uma variável contínua que assume valores no intervalo $[-1,+1]$. Um valor positivo indica que os perfis de competências tecnológicas das duas firmas consideradas caminham na mesma direção (para campos tecnológicos relacionados), indicando, portanto, a relação entre as atividades de ambas. Assim sendo, a ocorrência de uma efetiva relação entre as competências tecnológicas das fir-

$$
\begin{aligned}
& 17 \text { Considere } V T_{i}^{a} \text { e } V T^{b} \\
& v \operatorname{tr}_{i}^{a}=V \mathrm{TR}_{i}^{a}-\overline{\operatorname{VTR}^{a}} \\
& \text { como as distribuições da } \\
& \text { variável VTR assumidas pelo } \\
& \text { par de firmas } a \text { e } b \text {, onde cada } \\
& \text { atividade tecnológica } \\
& i=1, \ldots, 56 \text {. A estimativa do } \\
& \text { coeficiente de correlação de } \\
& \text { Pearson é definida como: } \\
& r=\frac{\sum v t r_{i}^{a} v t r_{i}^{b}}{\sqrt{\sum\left(v r_{i}^{a}\right)^{2}\left(v t r_{i}^{b}\right)^{2}}} \text { onde } \\
& \mathrm{e} v \mathrm{tr}_{i}^{b}=V T \mathrm{TR}_{i}^{b}-\overline{V T \mathrm{R}^{b}}, \\
& \operatorname{com} \overline{V T^{a}}=\frac{1}{56} \sum_{i=1}^{56} V \operatorname{TR}_{i}^{a} \\
& \mathrm{e} \overline{V T \mathrm{R}^{b}}=\frac{1}{56} \sum_{i=1}^{56} V \mathrm{TR}_{i}^{b} .
\end{aligned}
$$


mas de um dado par seria representada para valores desse coeficiente no intervalo $[0,+1] .{ }^{18}$ Para efeitos analíticos, este coeficiente de correlação de Pearson, $r$, dá então origem à variável $R T$, que reflete finalmente a relação tecnológica estabelecida entre as firmas dos 5.565 possíveis pares de firmas.

A quarta variável definida ao nível dessas possíveis combinações binárias de firmas reflete a diferença da intensidade de P\&D entre as firmas de cada par. Denominada Dif_IntP\&D, essa variável é definida como o módulo da diferença entre os índices de intensidades de P\&D das firmas de cada par. $\mathrm{O}$ índice de intensidade em P\&D de cada firma é medido como a média da razão entre gastos em $\mathrm{P} \& \mathrm{D}$ e receitas de vendas, de acordo com os dados da NSF,

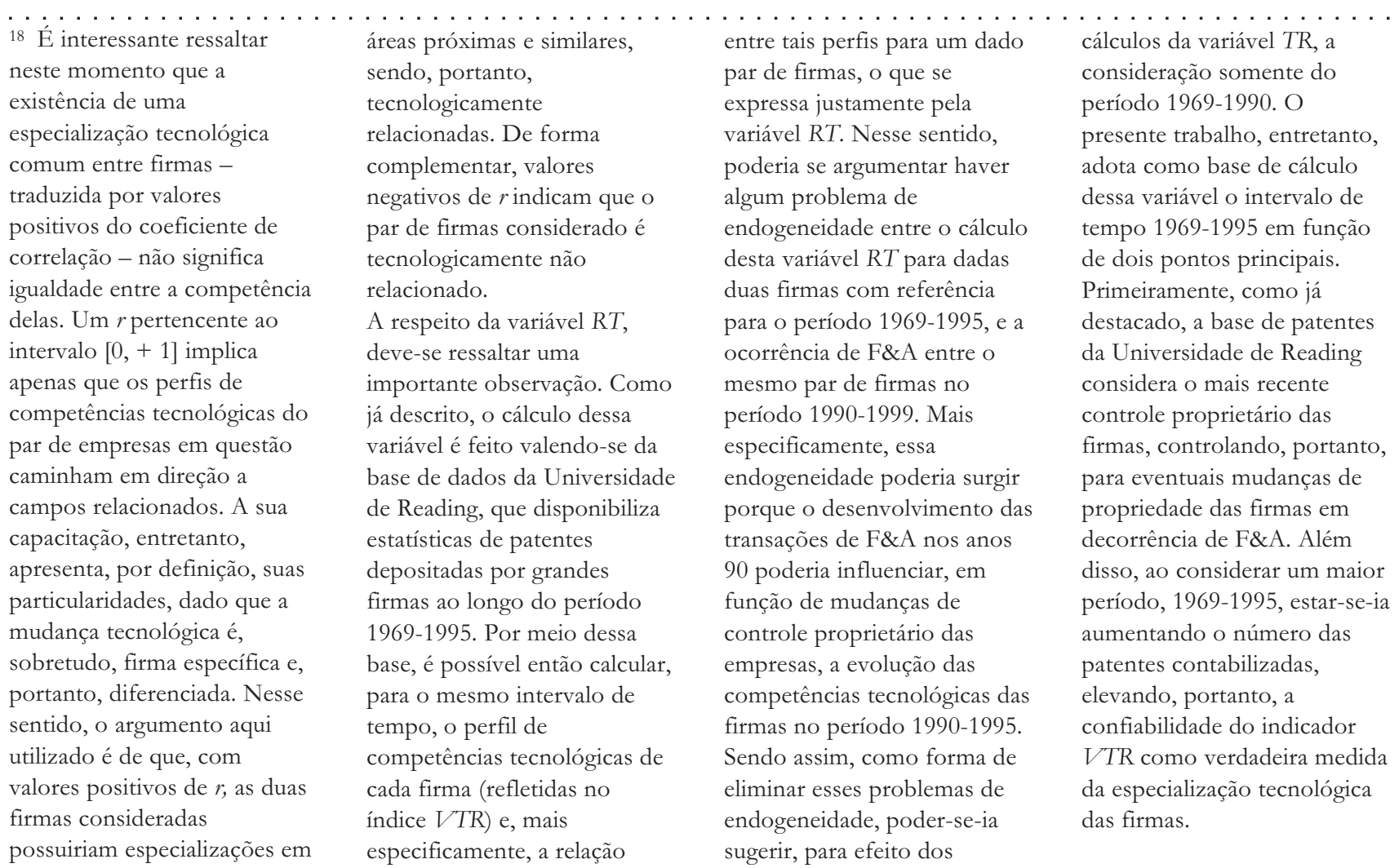


para os anos de 1996 e 1997. Quanto maior o valor da variável, maior é a diferença entre as firmas em termos de intensidade de P\&D.

A quinta e última variável retrata a diferença entre os tamanhos das firmas de cada par. Denominada Dif_TAMANHO, a variável é definida como o módulo da diferença entre os logaritmos naturais do tamanho das firmas de cada par. O tamanho de cada firma é aqui mensurado pelo valor médio das receitas de vendas para os anos de 1989,1990, 1998 e 1999, a partir da For tune. Maiores valores dessa variável indicam maior disparidade entre os tamanhos das firmas de cada combinação.

A Tabela 1 resume as definições de todas as variáveis utilizadas no presente trabalho.

\subsection{Métodos analíticos}

Para testar a hipótese $H 1$ - de que condicionantes internos à firma, refletidos por suas características tecnológicas e produtivas, exercem influência sobre a adoção de um caminho coerente de expansão via F\&A -, serão realizados testes de diferenças de média e análises econométricas.

\section{Tabela 1 Variáveis definidas ao nível das $\mathbf{5 . 5 6 5}$ combinações possíveis}

\begin{tabular}{|c|c|}
\hline$F \& A$ & $\begin{array}{l}\text { F\&A = } 1 \text { para pares de firmas que tenham realizado ao menos uma } \\
\text { transação de F\&A no período 1990-1999; caso contrário, F\&A = } 0\end{array}$ \\
\hline RT & $\begin{array}{l}\text { Valor do coeficiente de correlação de Pearson entre os perfis de } \\
\text { competências tecnológicas de cada par de firmas }\end{array}$ \\
\hline $\mathrm{RP}$ & $\begin{array}{l}\mathrm{RP}=1 \text {, para pares de firmas que possuem em comum o principal setor } \\
\text { de atividade; } \\
\mathrm{RP}=2 \text {, para pares de firmas que operam outro setor em comum, } \\
\text { que não a principal linha de atividade; } \\
\mathrm{RP}=3 \text {, para pares de firmas que não possuem nenhum setor de atividade } \\
\text { em comum }\end{array}$ \\
\hline Dif_IntP\&D & $\begin{array}{l}\text { Valor do módulo da diferença entre os índices de intensidades de P\&D das } \\
\text { firmas de cada par }\end{array}$ \\
\hline Dif_TAMANHO & $\begin{array}{l}\text { Valor do módulo da diferença entre os logaritmos (em base e) do tamanho } \\
\text { das firmas de cada par }\end{array}$ \\
\hline
\end{tabular}

Fonte: Elaboração própria. 
19 Como anteriormente destacado, das 5.565 possíveis pares de firmas, 132

desenvolveram ao menos uma transação de F\&A, localizando-se, assim, no grupo dos parceiros de F\&A. As 5.433 combinações binárias restantes encontram-se na categoria de não-parceiros de F\&A.

\subsection{1_ Testes de média}

Com o objetivo de delinear um grupo de controle, os 5.565 pares de firmas serão divididos, a partir da variável dicotômica $(F \& A)$, em duas categorias: parceiros de F\&A e não-parceiros de F\& $A .{ }^{19}$ Com base então nesses dois grupos, o objetivo é analisar o grau de relação produtiva e tecnológica para cada par de firmas. Em termos mais precisos, serão realizados testes de diferença de média para averiguar se os valores médios da relação tecnológica (refletida em RT) e da co-especialização produtiva (revelada pela variável multicategórica $R P$ ) apresentados pelos pares de firmas localizadas no grupo de parceiras de F\& $A$ são positivos e significativamente superiores em relação às respectivas médias apresentadas pelo grupo de firmas não-parceiras de $F \& A$. Dessa maneira, a realização desses testes permitirá averiguar se firmas que realizam F\&A entre si tendem a apresentar (ou não) características internas similares em termos de perfis produtivos e de competências tecnológicas, o que possibilitará então atestar a influência (ou não) dos condicionantes internos à firma sobre a adoção de uma direção relacionada no processo de diversificação via F\&A.

\subsubsection{Análise econométrica}

Como forma de aprofundar a compreensão da influência das características tecnológicas e produtivas internas à firma sobre a direção que essa imprime ao seu processo de diversificação via F\&A, serão desenvolvidas, além dos testes de mé- dia, análises econométricas. Será examinado, mais especificamente, se as firmas, respeitando as restrições que os seus recursos internos lhe definem, escolhem, para a realização de F\&A, parceiros cujos perfis tecnológicos e produtivos sejam relacionados aos seus. Assim, de forma a explicar as condições da seleção de parceiros para a realização de F\&A, será utilizado um modelo econométrico, no qual, a exemplo do procedimento adotado nos testes de média, as variáveis são definidas ao nível dos 5.565 possíveis pares de firmas. Dado que o fenômeno a ser explicado consiste na realização de F\&A entre as firmas de um par, a variável dependente do modelo corresponde à variável dicotômica $(F \& A)$.

Como variáveis independentes do modelo, serão utilizadas, primeiramente $R T$ e $R P$, as quais, como já definido, refletem, respectivamente, as relações tecnológicas e produtivas estabelecidas entre as firmas de um par. A seleção de parceiros de F\&A pode ser influenciada por outros fatores que não a existência de co-especializações tecnológicas e produtivas entre as firmas. Desse modo, serão utilizadas variáveis de controle que se referem a características relati- 
vas (entre as referidas empresas) no que diz respeito à intensidade de P\&D e ao tamanho, respectivamente, refletidas pelas variáveis Dif_intP\&D e Dif_TAMANHO.

Dado que a variável dependente $(F \& A)$ é dicotômica, a estrutura dos erros do modelo tende a ser binomial. Sendo assim, o método de mínimos quadrados ordinários, que assume uma distribuição normal dos erros, seria certamente ineficiente. Para evitar limitações desse tipo, a análise da seleção de parceiros para F\&A será feita com base na especificação do modelo LOGIT. Considerando especificamente as variáveis explicativas já apresentadas, a forma funcional exata do modelo a ser estimado é a definida no Modelo 1.

\section{3_Resultado dos testes de média}

A realização desses testes de diferença de média para averiguar a relevância das relações tecnológicas (RT) e produtivas ( $R P$ ) na explicação do desenvolvimento das operações de F\&A será feita em etapas sucessivas a seguir.

\section{1_Relação produtiva e transações de F\&A}

$\mathrm{Na}$ primeira etapa dos testes é examinado se as operações de F\&A tendem a ocorrer entre firmas que apresentam co-especialização produtiva ou entre firmas sem relação produtiva. Espera-se que as empresas tendam a desenvolver as referidas transações com parceiros que operem em linhas de atividade produtivas comuns.

Os resultados da Tabela 2 indicam que o percentual de pares de firmas que não possuem nenhuma linha de atividade em comum é maior entre a categoria de não-parceiros de $F \& A$ do que na de parceiros de $F \& A$. Na mesma direção, os resultados apontam que a proporção de pares de firmas que operam a mesma linha principal, ou possuem em comum outra atividade produtiva, também é superior para a categoria de firmas parceiras em F\&A. Tal evidência parece então indicar que transações de $F \& A$ entre empresas que não possuem relação produtiva tendem a ser menos provável de ocorrer do que as operações de $\mathrm{F} \& \mathrm{~A}$ intra-setoriais (i. e., para as quais os pares de firmas assumem $R P=1$ ou $R P=2$ ).

\section{Modelo 1}

$\ln \left[\frac{\operatorname{Prob}(F \& A)_{i}^{a b}}{1-\operatorname{Prob}(F \& A)_{i}^{a b}}\right]=\beta_{1}+\beta_{2} R T_{i}^{a b}+\beta_{3} R P(1)_{i}^{a b}+\beta_{4} R P(2)_{i}^{a b}+\beta_{5} D_{i f}$ IntP\& $D_{i}^{a b}+\beta_{6} D_{i f} T A M A N H O_{i}^{a b}+\varepsilon_{i}$ onde $a$ e $b$ indexam as firmas de cada um dos 5.565 pares analisados $(i=1,2, \ldots, 5.565)$. 
Tabela 2_Teste de média: relação produtiva de parceiros e não-parceiros de F\&A

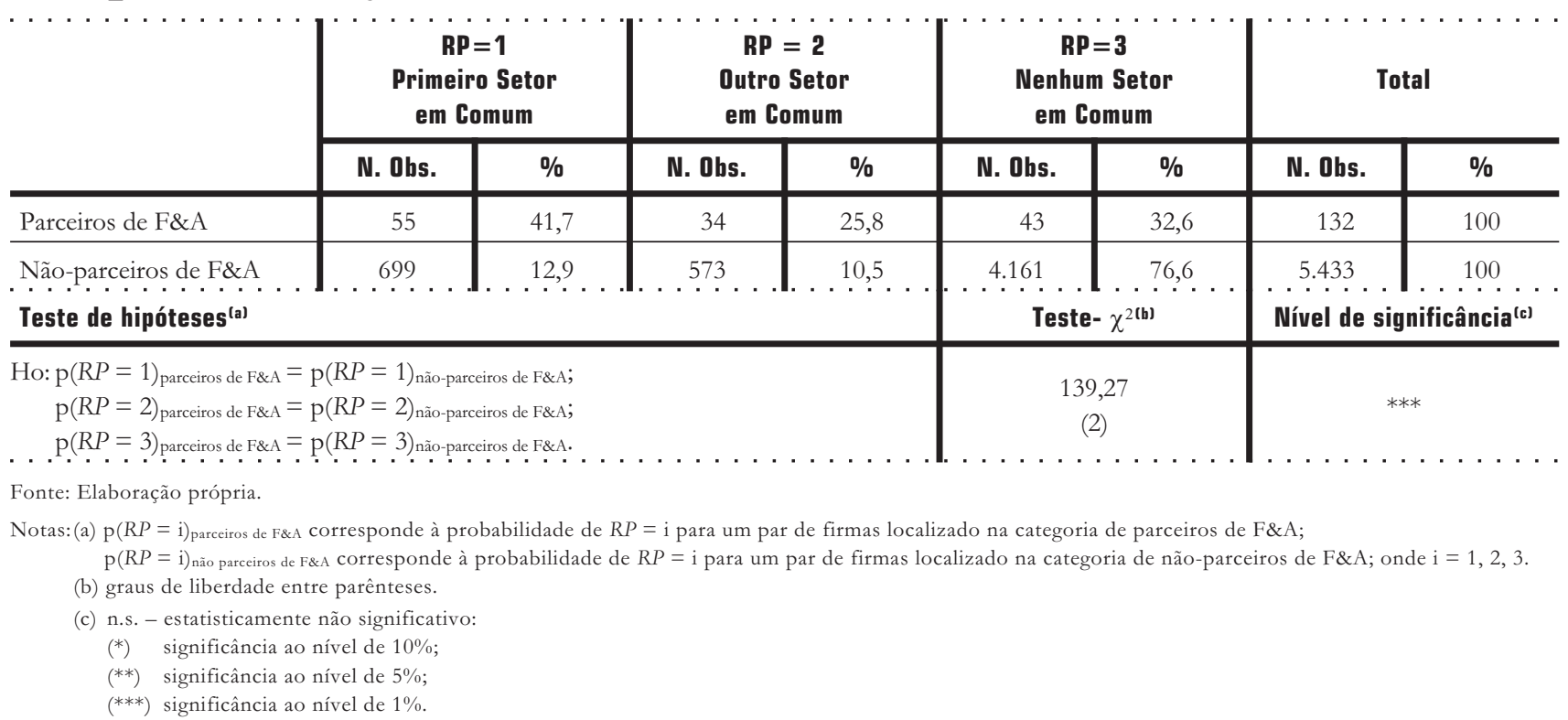

A significância (ao nível de 1\%) do teste $\chi^{2}$ indica a robustez dos resultados. Nesse sentido, para a amostra de empresas analisadas, existem fortes indícios de que a direção da diversificação via $F \& A$ assume um caminho relacionado em termos produtivos, sugerindo preliminarmente a confirmação da hipótese $H 1$.

\section{2_Relação tecnológica e transaçóes de F\&A}

Nesta segunda etapa, o objetivo é examinar a co-especialização tecnológica dos grupos de parceiros de $F \& A$ e não-parceiros de F\&A. Em outras palavras, busca-se verificar se as operações de F\&A ocorrem mais freqüentemente entre firmas caracterizadas por perfis relacionados de competências tecnológicas. Em consonância com a hipótese $H 1$, argumenta-se que um aumento no grau de relação tecnológica entre as firmas implicaria uma elevação dos ganhos potenciais de uma coordenação dos esforços tecnológicos entre elas, à medida que essas adquiririam maior capacidade de absorção para assimilar, em seus respectivos processos de aprendizado, o conhecimento técnico criado pela outra empresa (Cohen e Levinthal, 1990). Deste modo, é previsto que o desenvolvimento das operações de F\&A apresente uma associação positiva com a 
existência de relação tecnológica entre firmas parceiras.

Os resultados do teste-t dispostos na Tabela 3 indicam que, em média, as operações de F\&A tendem a ocorrer entre firmas que possuem perfis de competências tecnológicas relacionadas. Tais evidências sugerem, portanto, consistência, em termos tecnológicos, com a existência de caminho relacionado de diversificação via F\&A.

\subsection{Associação entre as relações tecnológicas e as produtivas}

Até o presente momento, os testes de média indicaram que, no caso das firmas analisadas, há uma tendência de desen- volvimento de F\&A entre firmas que se localizam na mesma indústria e que possuem especializações tecnológicas similares. Apesar de relevantes, tais resultados ainda não são suficientes para verificar seguramente a suposição feita em H1 de que as relações produtivas e tecnológicas ajudam a explicar a realização de operações de F\&A. Isso porque os dados utilizados não controlaram para a possibilidade de uma correlação entre as variáveis $R T$ e $R P$, o que poderia obviamente influenciar o desenvolvimento de transações de F\&A. Dessa forma, a presente etapa se destina a avaliar se as co-especializações produtivas e tecnológicas são relacionadas.

Tabela 3_ Teste de média: relação tecnológica de parceiros e não-parceiros de F\&A

\begin{tabular}{|c|c|c|}
\hline & N. Obs. & $\begin{array}{l}\text { Média } \\
\text { RT(a) }\end{array}$ \\
\hline Parceiros de F\&A & 132 & $\begin{array}{c}0,173 \\
(0,270)\end{array}$ \\
\hline $\begin{array}{l}\text { Não-parceiros de F\&A } \\
\ldots \ldots \ldots \ldots \ldots \ldots \ldots \ldots \\
\text { Teste de hipóteses }^{(b)}\end{array}$ & $\underset{\text { Teste-t }}{5.433}$ & 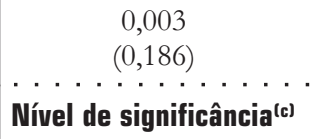 \\
\hline $\begin{array}{l}\text { Ho: } \mu(R T) \text { parceiros de F\&A }=\mu(R T)_{\text {não-parceiros de F\&A. }} . \\
\text { Fonte: Elaboração própria. } \\
\text { Notas: (a) Desvio padrão entre parênteses. } \\
\text { (b) Para o teste desta hipótese, são assumidas variância } \\
\text { (c) n.s. - estatisticamente não significativo: } \\
\left.\quad{ }^{*}\right) \text { significância ao nível de } 10 \% \\
\quad{ }^{* *} \text { significância ao nível de } 5 \% \\
(* * *) \text { siơnificância ao nível de } 1 \%\end{array}$ & S distintas e utiliza-se a aproxir & mação de Welch (1947). \\
\hline
\end{tabular}


Ao menos em termos teóricos, é possível esperar que tal associação seja positiva. De acordo com Cantwell e Fai (1999), o aspecto produtivo, que se observa ao nível do mercado através da emergência de novos produtos e da diversificação ou diferenciação de produtos já existentes, é amplamente relacionado com o aspecto tecnológico, dado que são as competências da firma, sobretudo as de natureza tecnológi$\mathrm{ca}$ - originadas a partir de um processo cumulativo de aprendizado ao nível da firma - as responsáveis pela criação e pelo refinamento de novos processos e produtos que o mercado recebe. Nesse sentido, espera-se que o padrão de competências tecnológicas seja mais similar para firmas que atuem nas mesmas atividades produtivas.

Particularmente em função dessa consideração teórica, seria também razoável prever, em termos empírico-metodológicos, uma relação positiva entre $P R$ e RT. Os valores bastante elevados para as estatísticas de teste obtidas até então levantam a possibilidade de que os referentes exames empíricos estivessem enviesados justamente pelo fato de não se ter considerado o aspecto da relação produtiva na análise que diz respeito à relação tecnológica e viceversa. Nesse sentido, por exemplo, pares de firmas que desenvolvem atividades pro- dutivas não comuns poderiam ter apresentado reduzidos valores para a variável RTh o grupo de controle por razões totalmente independentes da realização ou não de F\&A.

Para verificar a existência ou não de relação entre as variáveis $R T$ e $R P$, os 5.565 pares de firmas são classificados, na (Tabela 4), segundo as semelhanças produtivas com base no critério de existência do: primeiro setor em comum $(R P=1)$; outro setor em comum $(R P=2)$; e nenhum setor em comum $(R P=3)$. Para cada um desses grupos, foram calculados a média e o desvio padrão da variável $R T$.

Como se percebe, o valor da correlação entre os perfis de competências tecnológicas é maior para firmas que possuem o primeiro setor de atividade em comum $(R P=1)$. Do mesmo modo, pares de firmas que possuem em comum outra (que não a principal) linha de atividade produtiva $(R P=2)$ apresentam valor médio de $R T$ superior em relação às duplas de firmas que não possuem nenhuma atividade produtiva em comum $(R P=3)$. Dessa maneira, a hipótese nula de que os valores das relações tecnológicas (refletidas na variável RT) são iguais entre os grupos de firmas é rejeitada ao nível de $1 \%$ de significância em todos os três casos. 
Tabela 4_Teste de média: associação entre as relações tecnológicas e as produtivas

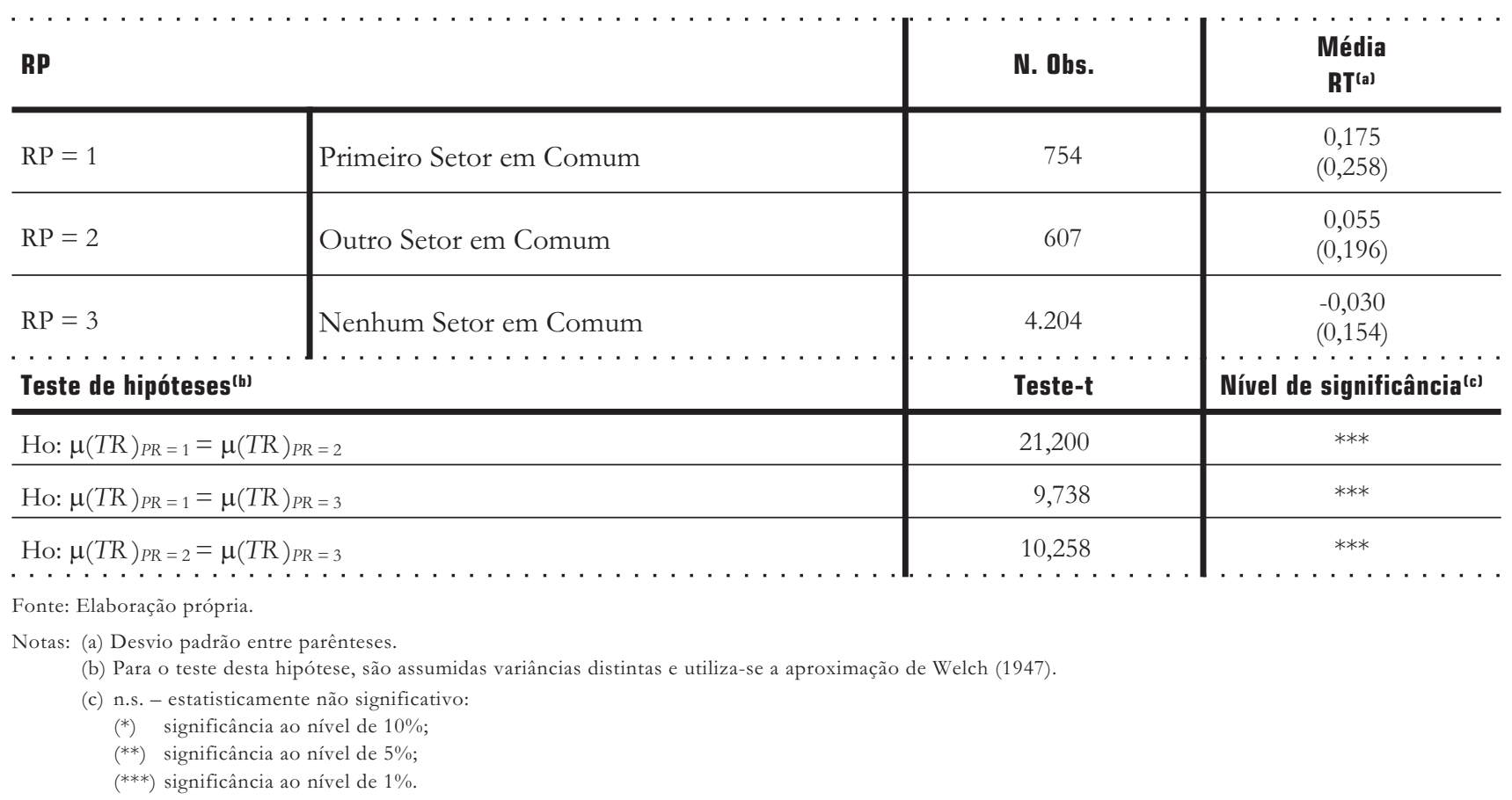

São encontrados, portanto, indícios de que os perfis de competências tecnológicas apresentam maior similaridade entre firmas que operam atividades produtivas comuns (seja $R P=1$, seja $R P=2$ ), o que, em outras palavras, significa dizer que as variáveis $R P$ e $R T$ são positivamente relacionadas. Assim sendo, tal associação deve ser levada em consideração no exame que pretende verificar qual o papel das relações produtivas e tecnológicas sobre a realização de uma operação de F\&A.

\section{4_Relações produtivas e tecnológicas e transações de F\&A}

Os resultados obtidos no teste anterior indicam a necessidade de um efetivo controle estatístico para o exame da influência das relações tecnológicas e produtivas sobre o desenvolvimento de operações de F\&A. Nesse sentido, enquanto os testes dispostos nas Tabelas 2 e 3 procuraram examinar se as operações de F\&A tendem a ocorrer, respectivamente, entre firmas que se encontram nos mesmos se- 
tores produtivos e que exibem perfis similares de especialização tecnológica, o presente teste pretende avaliar os efeitos combinados das variáveis $R P$ e $R T$ sobre a probabilidade de desenvolver uma F\&A. Em termos mais precisos, o teste de diferença de média avaliará a relevância da relação tecnológica sobre a probabilidade do desenvolvimento de uma operação de F\&A entre um par de firmas, controlando para a relação produtiva entre elas. É então previsto que pares de firmas que apresentem uma co-especialização produtiva (i. e., que operem linhas de atividade comuns, $R P=1 \mathrm{e}$ $R P=2$ ) e que sejam parceiras de $F \& A$ possuam, em média, perfis similares de especialização tecnológica.

Para tal finalidade, são identificadas na tabela abaixo seis categorias de pares de empresas, definindo se essas possuem em comum a primeira linha de atividade produtiva, uma outra linha, ou nenhuma, e se realizaram ou não operações de F\&A durante o período de análise de 1990-1999. Para cada uma dessas seis categorias, são calculados os valores médios e os desvios padrões da variável RT. Após isso, os testes de média são finalmente realizados para averiguar se não existem diferenças para $R T$ entre as referidas categorias (Tabela 5).
Os resultados indicam que pares de firmas que operam em setores de atividade comuns, sejam atividades principais ou não (para as quais $R P=1$ ou $R P=2$ ), e que desenvolveram entre si operações de F\&A, apresentam valores positivos para a variável $R T$, indicando, portanto, a posse de perfis de competências tecnológicas similares. Isso se aplica especialmente para firmas que possuem em comum os principais setores de atividade $(R P=1)$; neste caso, o valor de $R T$ é significativamente superior (ao nível de 1\%) para as firmas parceiras em $F \& A$ do que para as firmas não-parceiras em F\&A. Quando se consideram os pares de firmas que possuem em comum outros setores de atividade, que não os principais (para as quais $R P=2$ ), tal diferença apresenta-se ainda positiva e significativa, neste caso, ao nível de $5 \%$. Por último, quando se observam pares de firmas que operam atividades produtivas distintas (para as quais $R P=3$ ), é possível perceber que aqueles que desenvolveram entre si operações de F\&A apresentam perfis de especialização tecnológica com similaridade significativamente superior (ao nível de $10 \%$ ) aos pares de firmas localizados na categoria de não-parceiros de F\&A. Nesse sentido, a hipótese nula de que os valores médios da variável $R T$ são iguais entre as categorias de parceiros e não-parceiros de F\&A é rejeitada nos três casos e a níveis de significância estatística consideráveis. 
Tabela 5_ Teste de média: relações produtivas e tecnológicas de parceiros e não-parceiros de F\&A

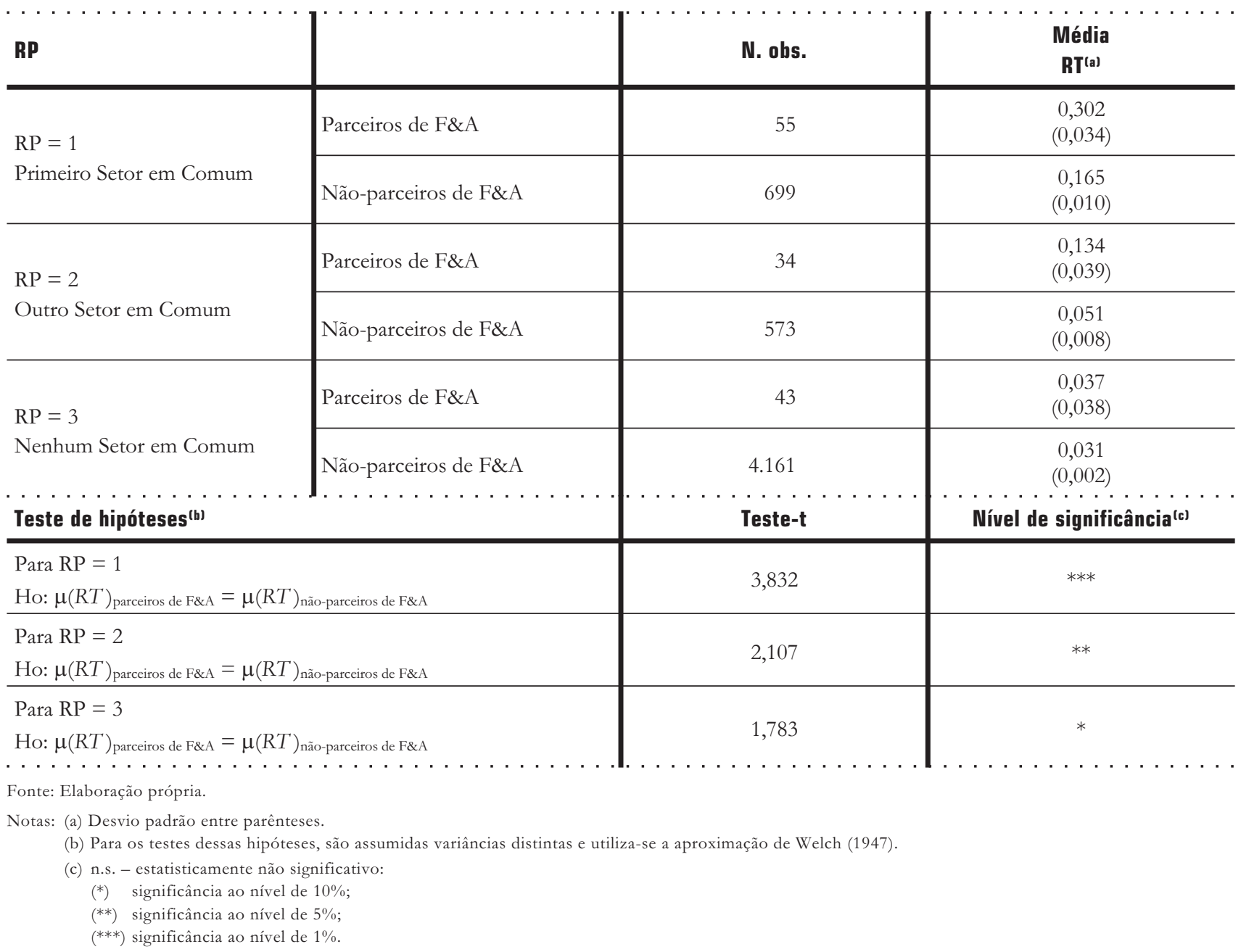


$\ldots \ldots \ldots$

${ }^{20}$ Existem duas formas

básicas de se adquirir

conhecimento: ou por

intermédio do investimento

interno da firma em

programas de $\mathrm{P} \& \mathrm{D}$, ou mediante a compra de outras

firmas cujos programas de

$\mathrm{P} \& \mathrm{D}$ tenham sido

bem-sucedidos ou possuam

potenciais de êxito. Esta

última estratégia tem a

vantagem de disponibilizar

maior quantidade de

informação sobre os

resultados de atividades de

$\mathrm{P \& D}$, que são naturalmente incertas (Hall, 1988, p. 70).

Como ressaltado em

Noteboom (1999), firmas

utilizam crescentemente

conhecimento produzido

externamente, e as operações

de F\&A seriam então uma

forma de acessar o

conhecimento (externo)

produzido por outra empresa.
De forma geral, os resultados sugerem fortemente que, quando se controla para as similaridades produtivas entre as firmas, existe ainda um considerável (e significativo) efeito positivo da relação tecnológica das firmas sobre a explicação de realização de F\&A, indicando desse modo que a existência de similaridades tecnológicas e produtivas está associada a maior probabilidade de desenvolvimento de operações de F\&A.

\section{4_ Resultados das análises econométricas}

Anterior a apresentações dos resultados da estimação do Modelo 1, vale discutir brevemente as previsões acerca do comportamento das variáveis explicativas.

De certa forma, as previsões para as variáveis $R T$ e $R P$ já foram apresentadas durante a realização dos testes de média. De todo modo, vale relembrar, novamente com base na argumentação teórica apresentada durante a seção inicial, que se espera encontrar evidências de que firmas prefiram realizar F\&A junto a parceiros que apresentem características tecnológicas relacionadas às suas. Assim sendo, é previsto um sinal positivo para o coeficiente de RT na equação do modelo LOGIT, o que designaria assim maiores probabilidades para a realização de F\&A entre pares de firmas que apresentem perfis de competências tecnológicas similares. Além das características tecnológicas, é esperado que as de ordem produtiva - refletidas na variável multicategórica $R P$ - também exerçam influência positiva sobre a coerência no processo de diversificação via $F \& A$.

Com relação às demais variáveis explicativas, algumas considerações preliminares relevantes devem ser feitas. A seguir são então apresentadas as previsões acerca dessas variáveis de controle.

Por meio da variável Dif_IntP\&D, pretende-se inferir, mais precisamente, a relevância das características tecnológicas na seleção de parceiros para F\&A. Enquanto o aspecto da relação tecnológica retratado pela variável $R T$ parece refletir particularmente a extensão da possível associação que se estabelece entre os perfis de competências tecnológicas de um par de firmas (Hagedoorn e Duysters, 2002, p. 77), a consideração de Dif_int $P \& D$ permite examinar a possível relação tecnológica entre as mesmas empresas em termos de profundidade, i. e., em termos de similaridade dos esforços de P\&D. A variável Dif_intP\&D assume ainda um interessante papel no modelo ao se considerar que as transações de F\&A constituem-se num meio para acessar conhecimento externo e potencializar a capacitação da firma. ${ }^{20}$ Nesse sentido, pode- 
se argumentar ainda que os esforços internos de P\&D em uma empresa são cruciais para habilitá-la a absorver e apropriar-se de possíveis spillovers que venham a surgir como decorrência das atividades de P\&D de outras firmas (Cohen e Levinthal, 1990). Sendo assim, a inclusão da variável Dif_intP\&D no modelo permite verificar se os esforços de P\&D de um par de firmas - refletindo, portanto, a forma como ambas se engajam na procura por novas oportunidades tecnológicas e na absorção de possíveis spillovers que podem derivar do P\&D produzido externamente - são relevantes para explicar a probabilidade de realização de uma F\&A.

Para efeito de previsões, é então esperado que firmas prefiram realizar operações de F\&A com parceiras que possuam intensidade de P\&D semelhantes, o que se refletiria num sinal negativo de Dif_intP\&D na equação do modelo LOGIT, dado que, para maiores diferenças entre as empresas em termos de P\&D, menor seria a probabilidade de elas realizarem uma operação de F\&A.

Optou-se por incluir também a variável Dif_TAMANHO como fator de controle no modelo como modo de ve- rificar se o tamanho relativo entre as firmas influencia a realização de transações de F\&A, independentemente das relações tecnológicas e produtivas entre elas. Para efeito de previsão, não é possível vislumbrar qual o sinal a ser apresentado pela variável Dif_TAMANHO na equação de $F \& A$, dado que a princípio é viável assumir que firmas tanto de tamanhos semelhantes quanto de tamanhos díspares possam realizar operações de F\&A entre si.

Na Tabela 6 seguem então os sinais previstos para a equação que explica a realização de F\&A.

A Tabela 7 apresenta finalmente o resultado da estimação dos coeficientes do modelo LOGIT para explicar a realização de F\&A.

Tabela 6_ Previsões das variáveis

\begin{tabular}{|c|c|}
\hline Variáveis independentes & Equação de F\&A \\
\hline RT & efeito positivo \\
\hline $\mathrm{RP}$ & efeito positivo \\
\hline Dif_IntP\&D & efeito negativo \\
\hline Dif_TAMANHO & efeito incerto \\
\hline
\end{tabular}

Fonte: Elaboração própria. 
Tabela 7_Resultado da estimação da equação de F\&A pelo método da máxima verossimilhança

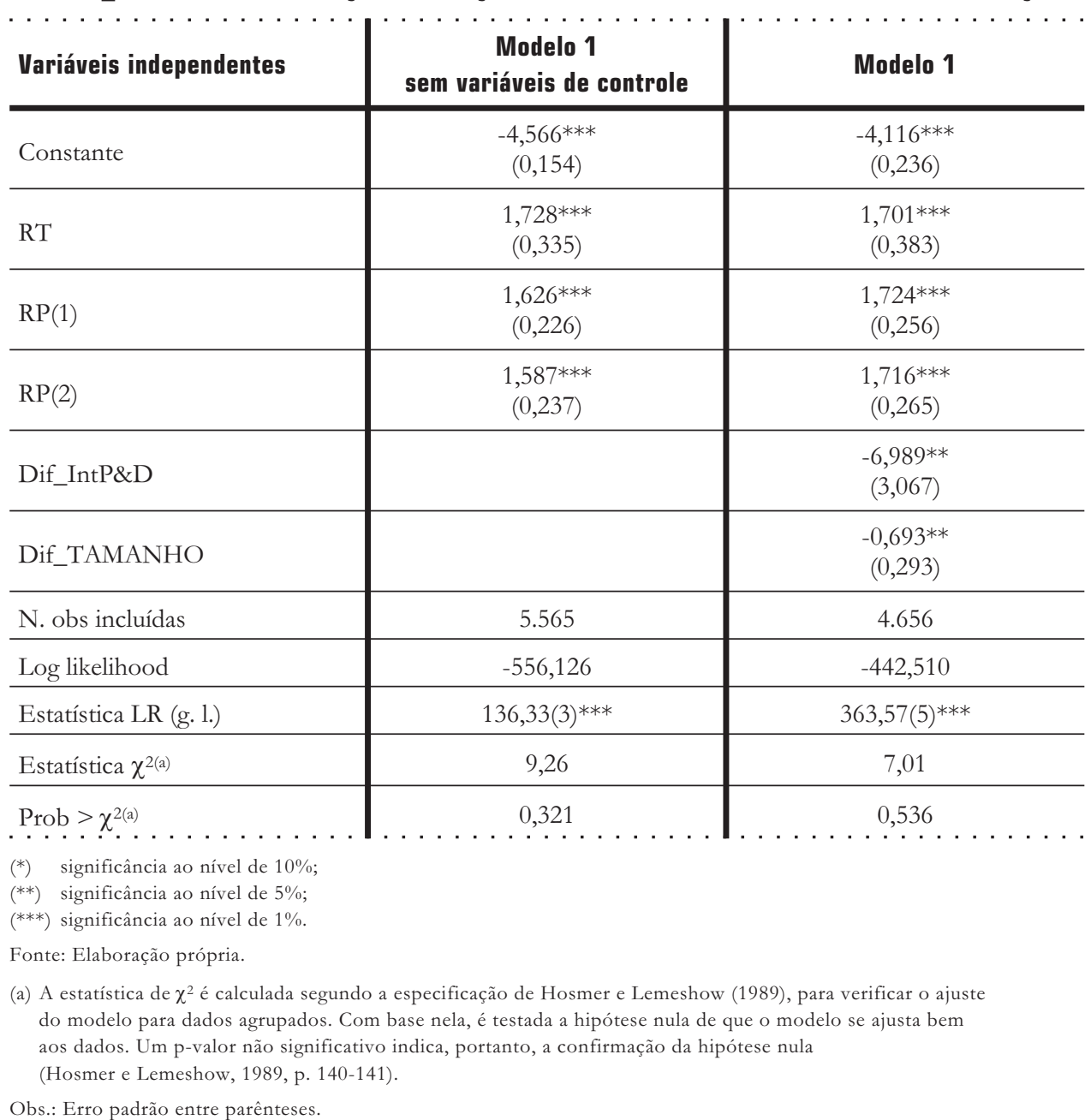


Considerando a primeira coluna dos resultados da Tabela 7 - para a qual não são computados os fatores de controle -, há sinais, como previsto na Tabela 6 , de que a probabilidade de um particular par de firmas desenvolver uma operação de F\&A é positivamente (e significativamente a 1\%) associada à variável RT. Desse modo, há evidências que sugerem ser a similaridade em termos de perfis de competências tecnológicas uma significativa influência para a seleção de parceiros de F\&A.

Na mesma coluna, os resultados demonstram que o poder de explicação da relação produtiva entre as firmas - refletida pela variável multicategórica $R P$ - é também considerável. A partir do coeficiente estimado para $R P(1)$, é possível inferir que pares de firmas que possuem a principal linha de atividade em comum (para os quais $R P=1)$ apresentam 5,60 mais chances de realizar uma operação de F\&A do que firmas que não possuem nenhuma atividade produtiva em comum. Os resultados indicam, da mesma forma, que, para pares de firmas que operam outra, que não a principal, atividade produtiva em comum (para os quais $R P=2$ ), a chance de desenvolver uma operação de F\&A é 5,56 maior do que a chance referente a pares de firmas que operam em setores de atividade distintos. Nesse sentido, a relação produtiva também influenciaria a seleção de parceiros de F\&A, sugerindo, portanto, que, além da interdependência de natureza tecnológica, as complementaridades produtivas são relevantes para o desenvolvimento de operações de F\&A.

Finalmente, ao considerar o vetor de variáveis de controle Dif_IntP\&D e Dif_TAMANHO, observa-se uma elevação da significância conjunta das variáveis e do ajuste do modelo: a estatística LR é significativa ao nível de $1 \%$, e o teste $\chi^{2}$ apresenta um aumento em seu p-valor. Mais importante ainda é o fato de que não há uma alteração dos sinais, tampouco da significância dos coeficientes de $R T, R P(1) \mathrm{e}$ $R P(2)$. A robustez desses resultados demonstra, assim, que, mesmo controlando para outros fatores que poderiam impactar a realização de $\mathrm{F} \& \mathrm{~A}$, há fortes indícios de que a existência de relação tecnológica e co-especialização produtiva influenciam de fato a seleção de parceiros, e, portanto, a realização de F\&A. Por exemplo, considerando as variáveis dummies nos patamares $R P(1)=1$ e $R P(2)=0$, e assumindo as demais variáveis explicativas em seus valores amostrais médios, a probabilidade de realização de uma F\&A para o par de firma que possui a maior similaridade tecnológica da amostra é de $30,7 \%$, enquanto que, para o par de empresas com a menor co-especialização tecnológica amostral, a probabilida- 
21 Vale destacar que, apesar de as variáveis $R T$ e $R P$ serem correlacionadas, como se identificou no teste de média disposto na Tabela 4, não houve problemas de multicolinearidade na estimação dos coeficientes do modelo LOGIT. Foi realizado o procedimento sugerido por Greene (1997, p. 421-422) de estimação de regressões auxiliares e não foram encontrados problemas desse tipo. Ademais, todos os resultados referentes a $R T$ e $\mathrm{R} P$ - com e sem a consideração das variáveis de controle - foram robustos a inclusão ou a exclusão, respectivamente de $R P$ e $R T$. de passa a ser de 2,61\%. Do mesmo modo, considerando $R P(1)=0$ e $R P(2)=1$ e as demais covariantes em seus valores médios, é previsto uma probabilidade de desenvolvimento de uma transação de F\&A de $30,6 \%$ para o par de firmas com a maior similaridade tecnológica amostral, enquanto para a combinação de firmas que possui a menor co-especialização tecnológica da amostra, a probabilidade de realização de uma F\&A é de $2,59 \%{ }^{21}$

No que diz respeito especificamente ao coeficiente da variável de controle Dif_IntP\&D, o resultado indica um sinal negativo (e significativo ao nível de 5\%), confirmando a previsão feita na Tabela 6 , e sugerindo assim que pares de firmas que apresentam maiores diferenças de intensidades de P\&D possuem menores probabilidades de realizar uma operação de F\&A. Tal resultado pode ser talvez esclarecido à luz do argumento apresentado em Hall (1988, p. 90-91) de que uma firma valoriza a intensidade de $\mathrm{P} \& \mathrm{D}$ de outras empresas (e possíveis parceiras de F\&A) a taxas crescentes em relação à sua própria intensidade de P\&D. Nesse sentido, como indicam os resultados obtidos para o caso da amostra aqui analisada, empresas parecem preferir realizar operações de F\&A com parceiros que apresentem uma intensidade de $P \& D$ semelhante às suas. Considerando então esse resultado para Dif_IntP\&D juntamente ao obtido para a variável $R T$, é possível apontar fortes sinais de que a similaridade das atividades tecnológicas entre firmas tanto em termos de extensão (refletida em RT) quanto em termos de intensidade (retratada por Dif_IntP\&D) - influencia a seleção de parceiros de F\&A.

Em relação à variável Dif_TAMANHO, o coeficiente negativo (e significativo ao nível de 5\%) sugere que F\&A entre firmas com tamanhos muito diferentes são menos prováveis de ocorrer, indicando, portanto, que empresas prefiram realizar F\&A com parceiras de tamanho semelhante.

\section{Considerações finais}

Este artigo procurou examinar o tema da coerência da diversificação corporativa via F\&A. Com esse intuito, foi suposto, a partir de (H1), que a firma, ao diversificar suas atividades por meio de operações de F\&A, seguiria um caminho relacionado no sentido de respeitar as restrições definidas pelas suas características tecnológicas e produtivas.

Para tal, fez-se uso das informações referentes às operações de F\&A desencadeadas por 106 empresas manufatureiras norte-americanas nos EUA, no período 1990-1999. Deve-se ressaltar aqui a nature- 
za distinta entre esse processo de $\mathrm{F} \& \mathrm{~A}$ nos EUA e o ocorrido no Brasil no mesmo período. Ao contrário dos EUA, onde as operações de mudança patrimonial refletem um processo tradicional da economia conforme as "ondas' de F\&A retratadas por Scherer e Ross (1990) -, o movimento de F\&A no Brasil, nos anos 90, está intimamente ligado (associado) às mudanças de contexto do período associadas à estabilidade macroeconômica, à liberalização da economia e à privatização. ${ }^{22}$

Analisando então o caso norte-americano, os resultados dos testes de média indicaram que as relações produtivas e tecnológicas entre as firmas ajudam de fato a explicar de forma significativa a realização de F\&A. As análises econométricas sugeriram ainda, de maneira mais direta, a confirmação da hipótese formulada: os resultados das estimativas demonstraram que a existência de co-especializações produtivas e tecnológicas contribui de forma significativa para a compreensão da seleção de parceiros de F\&A, mesmo quando se consideram outras características das empresas, como diferenças de tamanho e intensidade de P\&D. Desse modo, foram então encontradas evidências que sugerem que empresas preferem realizar operações de F\&A com outras firmas com as quais possuam similaridades tecnológicas e produti- vas, o que as leva, portanto, a preservar um caminho relacionado de diversificação.

Devem ser reconhecidas aqui também as limitações implícitas a um exame de natureza econométrica, que impedem a generalização de suas conclusões. Contudo, ao menos para o contexto aqui focalizado - referente às grandes empresas norte-americanas e suas transações de F\&A nos anos 90, nos EUA -, os resultados obtidos apontaram fatos bastante interessantes e que podem indicar o caminho para exames complementares aplicados a distintos contextos.

\author{
22 Para mais detalhes \\ sobre o processo de F\&A \\ no Brasil, nos anos 90 , \\ Ferraz e Iootty (2000) \\ e Rocha et al. (2001).
}




\section{Referências bibliográficas}

\author{
CANTWELL, J. Technological \\ innovation and multinational \\ corporations. Oxford: Basil \\ Blackwell, 1989.
}

CANTWELL, J. Historical trends in international patterns of technological innovation. In: FOREMAN-PECK J. (Ed.). New perspectives on the late victorian economy.

Cambridge: Cambridge University Press, 1991.

CANTWELL, J.; FAI, F. Firms as the source of innovation and growth: the evolution of technological competence. Journal of Evolutionary Economics, v. 9, p. 331-366, 1999.

CHANDLER, A. Scale and scope: the dynamics of industrial capitalism. Cambridge: Ma., Belknap Press, 1990.

COHEN, W. M. E; LEVINTHAL, D. A. Absorpitve capacity: a new perspective on learning and innovation. Administrative Science Quaterly, v. 34, p. 128-152, 1990.

FERRAZ, J. C.; IOOTTY, M. Fusões e aquisições e internacionalização patrimonial no Brasil nos anos 90. In: VEIGA, P. M. (Ed.). O Brasil e a economia global na virada do milênio. São Paulo: Relume Dumará, 2000.
GARY, S. The dynamics of diversification. In: INTERNATIONAL SYSTEM DYNAMICS CONFERENCE, QUEBEC CITY, 16 $6^{\text {th }}, 1988$.

GREENE, W. Econometric analysis. London: Prentice Hall International, 1997.

GUIMARÃES, E. A. Acumulacão e crescimento da firma: um estudo de organização industrial. Rio de Janeiro: Editora Guanabara, 1982.

HAGEDOORN, J.; DUYSTERS, G. The effect of mergers and acquisitions on the technological performance of companies in a high-tech environment. Technology Analysis and Strategic Management, v. 14, n. 1 , p. $67-85,2002$.

HALL, B. H. The effect of takeover activity on corporate research and development. In: AUERBACH, A. J. (Ed.). Corporate takeovers: causes and consequences. Chicago: The University of Chicago Press, 1988.

HOSMER, D. W.

LEMESHOW, S. Applied logistic regression. New York: John Wiley \& Sons, 1989.
JAFFE, A. B. Technological opportunity and spillovers of R\&D: evidence from firms' patents, profits and market value. American Economic Review, v. 76 n. 5, p. 984-1001, 1986.

KAY, N. Pattern in corporate evolution. Oxford: Oxford University Press, 1997.

LANGLOIS, R. N. Capabilities and coherence in firms and markets. In: MONTGOMERY, C. A. (Ed.). Resource-based and evolutionary theories of firm: towards a synthesis. Dordrecht: Kluwer Academic Publishers Group. 1995.

LEMELIN, A. Relatedness in the patterns of interindustry diversification. Review of Economics and Statistics, v. 64, p. 645-657, 1982.

MACDONALD, J. M. R\&D and the directions of diversification.

The Review of Economics and Statistics, v. 4, p. 351-374, 1985.

MONTGOMERY, C. A.

Corporate diversification. Journal of Economic Perspectives, v. 8, p. 163-178, 1994.
MOWERY, D. C. et al. Technological overlap and interfirm cooperation: implications for the resourcebased view of the firm. Research Policy, v. 27, p. 507-523, 1998.

PANZAR, J.; WILLIG, R.

Economies of scope. American Economic Review, v. 71, n. 2, p. 268-272, 1982.

PATEL, P.; PAVITT, K.

Europe's Technological

Performance. In: FREEMAN, C.; SHARP, M.; WALKER, W. B. (Ed.). Technology and the future of Europe: global competition and the environment in the 1990s. London: Frances Pinter. 1991.

PATEL, P.; PAVITT, K. The technological competencies of the world's largest firms:complex and path dependent, but not much variety. Research Policy, v. 26, p. 141-156, 1997.

PATEL, P.; PAVITT, K. The wide (and increasing) spread of technological competencies in the world's largest firms: a challenge to conventional wisdom. In: CHANDLER, A.; HAGSTRÖM, P.; SÖLVELL Ö. (Ed.). The dynamic firm. Oxford: Oxford University Press, 1999. 
PENROSE, E. T. The theory of the growth of the firm. New York: Wiley, 1959.

ROCHA, F. et al. Desempenho das fusões e aquisições na indústria brasileira na década de 90. Revista de Economia

Contemporânea, v. 5, p. 69-72, 2001 Número especial.

RUMELT, R. P. Strategy, structure and economic performance.

Cambridge, Ma: Harvard

University Press, 1974.

SCHERER, F. M.; ROSS, D.

Industrial market structure and economic performance. Boston: Houghton Mifflin, 1990.

SCOTT, J. T. Purposive diversification and economic performance. Cambridge: Cambridge University Press. 1983.

SRAFFA, P. The laws of return under competitive conditions. Economic Journal, v. 36, 1926.

TEECE, D. Economies of scope and the scope of an enterprise. Journal of Economic Behavior and Organization, v. 1, p. 223-247, 1980.

TEECE, D. An economic theory of multiproduct firms. Journal of Economic Behavior and Organization, v. 3, p. 39-63, 1982

TEECE, D. et al. Understanding corporate coherence: theory and evidence. Journal of Economic Behavior and Organization, v. 23 , p. 1-30, 1994.

TIROLE, J. The theory of industrial organization. Cambridge, Ma.: Mit Press, 1998.
WELCH, B. L. The generalization of student's problem when several different population variances are involved. Biometrika, v. 34 , p. $28-35,1947$.

WERNERFELT, B. A resource-based view of the firm. In: FOSS, N. J. (Ed.). Resources, firms and strategies: a reader in the resourcebased perspective. Oxford: Oxford University Press, 1997.

WERNERFEL, T, B.; MONTGOMERY, C. A.

Tobin's Q and the importance of focus in firm performance. The American Economic Review, v. 78, n. 1, p. 246-250, 1988.

WERNERFEL, T, B.; MONTGOMERY, C. A.

Diversification, Ricardian Rents and Tobin's Q. Resources, firms, and strategies. Oxford: Oxford University Press, 1997. p. 623-632.

WINTER, S. G. On coase, competence and the corporation. Journal of Law and Economic Organization, v. 4, p. 163-180, 1987.

WOOD, A. Diversification, merger and research expenditure: a review of empirical studies. In: MARRIS, R.; WOOD, E A. (Ed.). The corporate economy: growth, competition and innovative potential. Londres, Macmillan, 1971.
- Gostaríamos de agradecer

- a Thomson Financial pelo

- fornecimento dos dados de

: F\&A. A John Cantwell

: agradecemos pelas sugestões

: e pela infra-estrutura de pesquisa.

- durante a minha permanência

- na Universidade de Reading,

: Inglaterra. A João Carlos

- Ferraz, David Kupfer, Frederico:

- Rocha e Paula Bastos

- agradecemos pelos comentários

- feitos ao capítulo da tese

- de doutorado que deu origem

: a este artigo. Agradecemos ainda

- os comentários dos dois

- pareceristas anônimos desta

- revista. Guardamos para nós

- a responsabilidade por qualquer

- tipo de erro.

E-mail de contato dos autores

- chicoebeling@yahoo.com.br

- miootty@ie.ufrj.br

Artigo recebido em agosto de 2005

- aprovado em novembro de 2007.

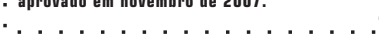




\section{Lista das 106 firmas da amostra}

\begin{tabular}{|c|c|c|c|}
\hline 1 & Abbott Laboratories Inc & 21 & Caterpillar Inc \\
\hline 2 & Air Products and Chemicals, Inc & 22 & Champion International Corporation \\
\hline 3 & Alcoa Inc & 23 & Chevron Corporation \\
\hline 4 & American Home Products Corporation & 24 & Clorox Company, The Inc \\
\hline 5 & American Standard Companies Inc & 25 & Coca-Cola Company Inc, The \\
\hline 6 & Archer Daniels Midland Company & 26 & Colgate-Palmolive Company Inc \\
\hline 7 & Armstrong Holdings Inc & 27 & Compaq Computer Corporation \\
\hline 8 & Ashland Inc & 28 & Conagra Inc \\
\hline 9 & Baker Hughes Incorporated & 29 & Cooper Industries Inc \\
\hline 10 & Ball Corporation & 30 & Corning Incorporated \\
\hline 11 & Becton, Dickinson and Company Inc & 31 & Crown Cork \&Seal Company Inc \\
\hline 12 & Black \& Decker Corporation, The & 32 & Cummins Engine Company, Inc \\
\hline 13 & Boeing Company, The Inc & 33 & Dana Corporation \\
\hline 14 & Boise Cascade Corporation & 34 & Deere \& Company Inc \\
\hline 15 & Borg-Warner Automotive Inc & 35 & Dover Corporation \\
\hline 16 & Bristol-Myers Squibb Company Inc & 36 & Dow Chemical Company, The Inc \\
\hline 17 & Brunswick Corporation & 37 & $\begin{array}{l}\text { Du Pont, E. I. De Nemours and } \\
\text { Company Inc }\end{array}$ \\
\hline 18 & Bw Holdings, Llc & 38 & Eastman Kodak Company Inc \\
\hline 19 & Cabot Corporation & 39 & Eaton Corporation \\
\hline 20 & Campbell Soup Company Inc & 40 & EMC Corporation \\
\hline
\end{tabular}




\section{Lista das 106 firmas da amostra}

\begin{tabular}{|c|c|c|c|}
\hline 41 & Emerson Electric Co Inc & 64 & ITT Industries, Inc \\
\hline 42 & Engelhard Corporation & 65 & Johns Manville Corp \\
\hline 43 & Ethyl Corporation & 66 & Johnson \& Johnson Inc \\
\hline 44 & Exxon Mobil Corporation & 67 & Johnson Controls Inc \\
\hline 45 & FMC Corporation & 68 & Kellogg Company Inc \\
\hline 46 & Ford Motor Company Inc & 69 & Kimberly-Clark Corporation \\
\hline 47 & Fortune Brands Inc & 70 & Lilly, Eli and Company \\
\hline 48 & General Electric Company Inc & 71 & Litton Industries, Inc \\
\hline 49 & General Motors Corporation & 72 & Lockheed Martin Corporation \\
\hline 50 & Gillette Company, The Inc & 73 & Merck \& Co, Inc \\
\hline 51 & Goodrich B F Company, The Inc & 74 & $\begin{array}{l}\text { Minnesota Mining \& Manufacturing } \\
\text { Company Inc }\end{array}$ \\
\hline 52 & $\begin{array}{l}\text { Goodyear Tire \& Rubber Company, } \\
\text { The Inc }\end{array}$ & 75 & Motorola, Inc \\
\hline 53 & Grace, W.R. \& Co & 76 & National Semiconductor Corporation \\
\hline 54 & GTE Corporation & 77 & Northrop Grumman Corporation \\
\hline 55 & Halliburton Company & 78 & Olin Corporation \\
\hline 56 & Harris Corporation & 79 & Perkinelmer, Inc \\
\hline 57 & Hercules Incorporated & 80 & Pfizer Inc \\
\hline 58 & Hewlett-Packard Company Inc & 81 & Pharmacia Corp \\
\hline 59 & Honeywell International Inc & 82 & Philip Morris Companies Inc \\
\hline 60 & Ingersoll-Rand Company Inc & 83 & Phillips Petroleum Company Inc \\
\hline 61 & Intel Corporation & 84 & Pitney Bowes Inc \\
\hline 62 & $\begin{array}{l}\text { International Business Machines } \\
\text { Corporation }\end{array}$ & 85 & Polaroid Corporation \\
\hline 63 & International Flavors \& Fragrances Inc & 86 & PPG Industries Inc \\
\hline
\end{tabular}




\section{Lista das 106 firmas da amostra}

(conclusão)

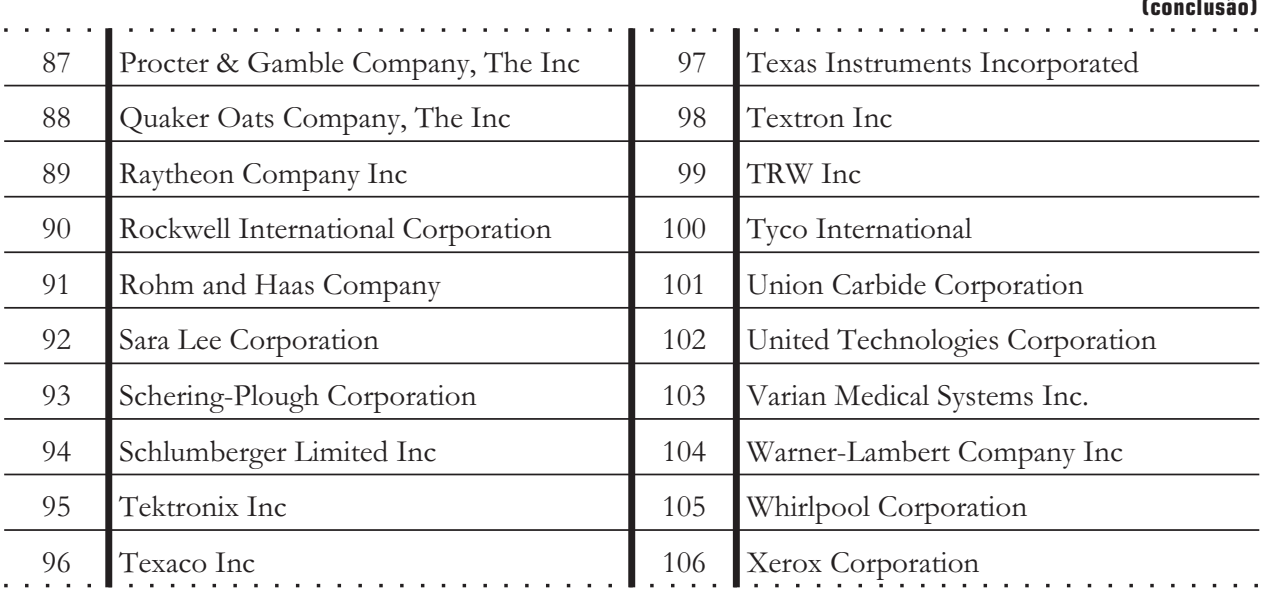

Fonte: Elaboração própria. 